\title{
Resilience Factors Among Police Investigators: Hardiness-commitment a Unique Contributor
}

\author{
Tonje Fyhn $^{1}$ - Kristin Konglevoll Fjell ${ }^{2}$ Bjørn Helge Johnsen ${ }^{2}$ \\ Published online: 27 October 2015 \\ (C) The Author(s) 2015. This article is published with open access at Springerlink.com
}

\begin{abstract}
The aim of this study was to explore the role of individual and contextual buffers against the effects of work stress among police investigators. 156 Norwegian police investigators were assessed on the predictor variables psychological hardiness, work engagement, social support, and meaningfulness, and on the outcome variables of burnout, subjective health complaints, and self-reported sick leave. Hierarchical regression analysis showed that psychological hardiness predicted the variance in burnout beyond that of work engagement, social support, and meaningfulness. When the investigators were divided into two groups based on their field, investigators of assault crime showed higher scores than the group consisting of forensics and investigators of fire, financial, and environmental crime on the variables psychological hardiness, social support, meaningfulness, and subjective health complaints. No differences between the groups were found on burnout, sickness absence, and work engagement. The findings show the importance of resilience factors for coping with work stress, with the commitment dimension of hardiness being particularly important.
\end{abstract}

Keywords Police investigators $\cdot$ stress $\cdot$ resilience $\cdot$ hardiness $\cdot$ commitment $\cdot$ burnout

Tonje Fyhn

tonje.fyhn@uni.no

1 Uni Research Health, Uni Research, Bergen, Norway

2 Department of Psychosocial Science, University of Bergen, Bergen, Norway

\section{INTRODUCTION}

\section{Background}

The majority of research investigating police work stressors focuses on the nature of frontline policing, such as patrolling, arrests, and callouts, or organizational stressors. However, less attention has been paid to police investigators as a group, and the stressors they face. The organizational distinction of these two groups of employees should be reflected in police studies, as their respective work tasks differ substantially in nature. While patrolling officers face immediate, objective threats, the stress experienced by police investigators can be characterized as second hand, subjective threats, as they deal firsthand with victims of serious crimes and their next of kin, graphic depictions, media attention in particular cases, and court deadlines. A factor analysis of police tasks, conducted by Brown and colleagues (1999), identified dealing with victims of traumatization as a distinct factor contributing to work stress among police officers. However, within the field of investigation there are also different types of victim trauma that investigators deal with. For example, while financial crime investigators will mainly be exposed to psychological and emotional trauma, assault investigators are exposed to externally inflicted victim trauma. Assault crime will often be motivated by aggression, and the trauma is often physical as well as psychological and emotional in nature, which hypothetically may cause more strain among helpers, such as investigators. When studying investigators, distinguishing them by the nature of their work tasks as well as the nature of the victim trauma they face, may identify sources of stress and sources of resilience among investigators.

The purpose of the current study is to investigate personal and contextual factors contributing to buffer the effects of stress among investigators of sexual and physical assault, as 
well as investigators of other, less offensive crime, such as financial or environmental crime.

\section{Factors under study}

Studies conducted among Norwegian police workers as a whole show that they do not show a higher level of stress responses such as burnout, when compared with other occupations such as journalists, construction managers, and air traffic controllers (Richardsen and Martinussen 2005; Martinussen et al. 2007). However, one study including a sample of 3000 police workers found that they reported higher levels of subjective health complaints compared to physicians (Berg et al. 2006).

On one hand, the lack of consistent findings regarding the relationship between police work and reported stress may mean that the stressors unique to police work do not have the deteriorating effect as traditionally assumed. A different approach, however, is to consider which traits or coping styles among police officers may serve as buffers to diminish the effect of operational stressors.

Hardiness is a personality style that influences the individual to cope with challenges in a constructive and proactive manner (Kobasa et al. 1982). A meta-analysis including 180 studies on hardiness concluded that hardiness, and in particular the commitment dimension, is an important resource to cope with stress, showing negative relationships with stressors and passive coping, and positive relationships with active coping and performance (Eschleman et al. 2010). One study of police officers found that hardiness-commitment was negatively correlated with depression and psychological distress (Andrew et al. 2008). Additionally, the meta-analysis showed that hardiness explained unique variance over other personality traits, such as the big five traits.

Hardy individuals tend to reframe stressful events into opportunities for growth, and evaluate challenges in a positive way (Bartone 2006; Kobasa et al. 1982). Furthermore, hardy individuals assume that making conscious choices that hold opportunities, although not promising a positive outcome, leads to personal development and fulfillment (Maddi 2002). This world-view creates a heightened awareness of their own role in influencing their circumstances. It is fair to assume that it is this positive and pro-active world-view which influences stress-related outcomes among hardy individuals.

The hardiness measure consists of three factors: Commitment, control, and challenge (Kobasa 1979). Individuals high in these three domains generally seem to function and perform under difficult or even extreme conditions, by believing they can influence their situation, and positively reframe challenges they face (Kobasa et al. 1982). Studies have shown hardiness to be a predictor of success both in highly stressful military selection programs as well as in academic performance (Johnsen et al. 2013; Sheard 2009; Zach et al. 2007). It is reasonable to assume that police investigators, being a specially trained group working within complex and challenging fields, will report high levels of hardiness. A key unique aspect of the current study is that it examines psychological hardiness as a predictor of burnout among police investigators as a separate group in the police force.

In addition to using the measure of hardiness as an outcome predictor, the current study also includes traditional buffers against work stress, such as social support, work engagement and meaningfulness. The majority of research on work-related stress acknowledges these factors as important buffers against the effects of work stress (Johnson and Hall 1988; DeLongis et al. 1988; Kobasa 1979; Southwick et al. 2005). The factors have shown to be negatively correlated with outcomes such as burnout and subjective health complaints (Eriksen and Ursin 1999; Schaufeli et al. 2006), and are therefore included in the current study.

The outcome variables in the current study include burnout, subjective health complaints, and self-reported sickness absence. Burnout, as operationalized by Maslach and Jackson (1981), is a measure of work strain in work stress research, particularly in studies conducted among helping professions (Schaufeli et al. 2008). It is a prolonged stress-response to conditions in the work-setting, such as work overload, lack of social support, and requirements to express or suppress emotions at work, and to be empathic (Maslach et al. 2001; Zapf et al. 2001). Burnout is comprised of the three factors emotional exhaustion, cynicism, and professional inefficacy. Emotional exhaustion is most reported and most researched of the three, and describes the core of the burnout concept: One is simply worn out. While the factor cynicism describes one's relationship to people one is involved with at work, professional inefficacy describes a feeling of not accomplishing as much as one is capable of (Maslach et al. 2001). Studies among police officers suggest that the factors cynicism and inefficacy are especially high compared to occupations within medicine, teaching and social services (Schaufeli and Enzmann 1998).

Several studies have consistently shown positive relationships between burnout and psychosomatic complaints (Jourdain and Chênevert 2010; Martinussen et al. 2007; Piko 2006). Subjective health complaints are the most common cause for sick leave in the Norwegian workforce (Ihlebæk et al. 2004). These complaints cannot be explained by physiological changes, and include among others musculoskeletal pain, gastrointestinal complaints, and migraine. A Norwegian study of subjective health complaints among police workers showed a higher prevalence of these complaints compared to other occupations (Sandal et al. 2006). The outcome variables and their effects represent a significant cost to the individual as well as the organization, and understanding their counterparts may contribute to reducing their prevalence and severity. 


\section{Hypotheses}

The current study aims at investigating the effects of the strain experienced by police investigators, as well as the individual and contextual buffers against these effects. In the current study, social support and personality traits are included in the same analysis. By doing so, we are able to distinguish their respective contribution to the variance in the different outcome variables.

Based on previous research showing hardiness to explain the variance in stress-related outcomes beyond that of a number of other variables, it is hypothesized that hardiness will predict the variance in burnout among police investigators beyond that of traditional buffers against stress, namely social support, work engagement and meaningfulness.

Furthermore, based on the assumption that investigators of assault crime are a self-selected group exhibiting traits that enable them to cope well, it is hypothesized that this group of investigators will report higher levels of hardiness than forensics and investigators of fire, financial, and environmental crimes.

\section{METHOD}

\section{Subjects}

Participants in the study were 156 Norwegian police investigators employed at Oslo Police Department or the National Criminal Investigation Service (Norway). The response rate was $76 \% .205$ questionnaires were distributed. 47 people were non-completers, and two responses were discarded due to lack of demographic and background information. The high response rate can be explained by a few factors: These departments rarely allow researchers to enter their organization and interrupt the employees' work day; employees were given time during work hours to complete the survey; and the survey only took 10-15 minutes to complete.

Men constituted 59\% of the sample. Mean age $(n=147)$ was 41.4 years $(\mathrm{SD}=7.8)$. Half of the participants were investigators of assault crime $(n=78)$, and the other half were forensics, or investigators of fire, financial, or environmental crime $(\mathrm{n}=78)$.

\section{Questionnaires}

Psychological hardiness was measured by Dispositional Resilience Scale 15-R, (Hystad et al. 2010), which consists of 15 items measuring the three factors challenge, commitment, and control, scored on a 4-point likert scale. Sample items are "Changes in routine are interesting to me" (challenge); "Most days, life is really interesting and exciting for me" (commitment); and "How things go in my life depends on my own actions" (control). Cronbach's alpha for the scale was as follows: Total scale $(\alpha=0.79)$, commitment $(\alpha=$ $.70)$, challenge $(\alpha=.71)$; and control $(\alpha=.75)$.

Social support was measured using 13 items from Job Content Questionnaire, developed by Karasek et al. (1998). The items measure instrumental and emotional support, as well as hostile behavior, from both superiors and coworkers, scored on a 4-point likert scale. Sample items are "My colleagues care about me", and "My superior provides help when needed". Cronbach's alpha for the Job Content Questionnaire was $(\alpha=.90)$.

Work engagement was measured using Utrecht Work Engagement Scale (Schaufeli and Bakker 2003). The scale consists of nine items measuring vigor, dedication, and absorption, scored on a 7-point likert scale. Sample items are "When I get up in the morning, I feel like going to work" (vigor); "I am enthusiastic about my job" (dedication); and "I am immersed in my work" (absorption). Cronbach's $\alpha$ was as follows: For the total scale $(\alpha=.96)$, vigor $(\alpha=.90)$, dedication $(\alpha=.93)$, and absorption $(\alpha=.88)$. Similarly, other studies among police officers have shown a Cronbach's alpha of .90 for the total scale (Biggs et al. 2014), and .91 for vigor, .92 for dedication, and .92 for absorption (Gillet et al. 2013).

The scale measuring meaningfulness was constructed by the authors, based on interviews conducted a year prior to the current study. The interviews were part of a master's degree course, and respondents were assault investigators in a different part of the country. The items build on the factors that were most often mentioned when investigators talked about meaningfulness in their job: Personal contribution to the society, and appreciation, or lack thereof, by the public. The scale was scored on a 4-point likert scale. Cronbach's alpha for the four items was $(\alpha=.75)$.

The scale consisted of the following items:

a. I feel that the work I do makes a difference in our society

b. I feel that I help restore justice.

c. I feel that the work is rewarding.

d. My impression is that the public understands the importance of our work.

Outcome variables were burnout, subjective health complaints, and self-reported sickness absence. Burnout was measured using Maslach Burnout Inventory (Maslach et al. 1986), which consists of 16 items measuring exhaustion, cynicism, and reduced professional efficacy on a 7-point likert scale. Sample items are "I feel emotionally drained from my work" (exhaustion); "I just want to do my job and not be bothered" (cynicism); and "I can effectively solve the problems that arise in my work" (reduced professional efficacy). For the Maslach Burnout Inventory, the Cronbach's alpha for the total scale was $(\alpha=.82)$, and for the subscales as follows: Exhaustion $(\alpha=.82)$, cynicism $(\alpha=.90)$, and reduced professional 
efficacy $(\alpha=.71)$. In comparison, a different study measuring burnout among Norwegian police officers, had a Cronbach's alpha of .86 for exhaustion, .80 for cynicism, and .79 for reduced professional efficacy (Martinussen et al. 2007).

The scale Subjective Health Complaints (Eriksen et al. 1999) consists of a list of 29 symptoms, such as "Migraine"; "Extra heartbeats"; and "Neck pain". The items make up five subscales, measuring the duration and intensity of musculoskeletal pain $(\alpha=0.76)$, pseudoneurological complaints $(\alpha=.75)$, gastrointestinal problems $(\alpha=.52)$, allergy $(\alpha=.66)$, and flu-like symptoms $(\alpha=.75)$, on a 4-point likert scale.

Self-reported sick-leave was measured by asking the respondents whether they had been away from work more than 14 days the last 12 months, and how many self-certified sickleave days they had the last 12 months. Respondents were also asked whether they attributed the sickness absence to workrelated factors.

Sum scores were created for all scales.

\section{Procedure}

Questionnaires were distributed through department leaders to all employees, and employees were provided time during work hours (i.e. after department meetings) to complete the questionnaires. Each questionnaire contained an information page, which explained the purpose of the study, that participation was voluntary and anonymous, and that no responses could be traced back to individuals. Questionnaires were returned in a box located in each department, which was collected by the researchers after a two-week period. Employees on sick leave were also invited to participate in the study, and were provided envelopes with pre-paid postage. Based on the departments' field of work, the respondents were categorized into two groups: Group 1 consisted of forensics, financial crime, fire crime, and environmental crime investigators. Group 2 consisted of officers investigating sexual offences and violence. Each group consisted of 78 respondents. Mean age was approximately the same in each group; 40 years (SD $=7.07)$ for group 1 and 43 years $(\mathrm{SD}=8.23)$ for group 2 . However, group 1 consisted of $73 \%$ men, while group 2 consisted of $45 \%$ men.

\section{Statistical analyses}

Analyses were performed using SPSS 22. Correlational analyses were performed on all variables. Variation in degrees of freedom was caused by missing data (MD). However, there were few MD (response rate for burnout: 90\%; social support and work engagement: $96 \%$; subjective health complaints, hardiness and meaningfulness $99 \%$ ).
Hierarchical regression analysis was performed using burnout as the outcome variable. To check for co-variates, age, experience in the police, and experience in current position was added as control variables in step 1 , and gender was added in step 2. Marital status and Job Content Questionnaire (social support) were added in step 3, and meaningfulness and work engagement were added in step 4. Finally, hardiness was added in step 5 . The preliminary multiple regression analysis showed the dimension of commitment to be the only hardiness dimension giving a significant contribution to the variance in burnout, so this was the only hardiness dimension included in step 5 of the hierarchical regression analysis.

$T$-tests were performed in order to examine significant differences between the two investigator groups on all variables: Psychological hardiness, meaningfulness, social support, subjective health complaints, burnout, work engagement, and sickness absence.

\section{RESULTS}

The correlational analysis (Table 1) showed negative relationships between all predictor variables and burnout, as well as a moderate negative relationship between social support and subjective health complaints. The sub-category "musculoskeletal complaints" was the most reported health complaint (Table 2), and was positively correlated with sickness absence.

In step 1 of the hierarchical regression analysis (Table 3), age, years of experience in the police, and years of experience in current position explained 1.9\% of the variation in burnout, but this was not significant $(\mathrm{p}=.485)$. When gender was added in step 2 , this increased slightly, to $2.4 \%$ ( $R$ square change $=0.5, F$ change $(1,128)=.63, \mathrm{p}=.546)$. As social support (Step 3), namely marital status and job support, was added, the explained variance increased to $30 \%$, and this was significant $(R$ square change $=27.7, F$ change $(2,126)=24.92, \mathrm{p}=.000)$. When meaningfulness and work engagement were added (Step 4), this increased to $50.8 \%(R$ square change $=20.7, F$ change $(2,124)=$ 26.12, $\mathrm{p}=.000$ ). As hardiness-commitment was added (Step 5), the final model explained $54.4 \%$ of the explained variance in burnout $(R$ square change $=3.6, F$ change $(1,123)=9.72, \mathrm{p}=.000)$.

In the final model, social support, marital status, work engagement, and hardiness-commitment were the only significant contributors.

$T$-tests were performed to examine differences in scores between the two groups of investigators on the outcome and predictor variables. The group working with assault crimes scored significantly higher on hardiness, meaningfulness, 


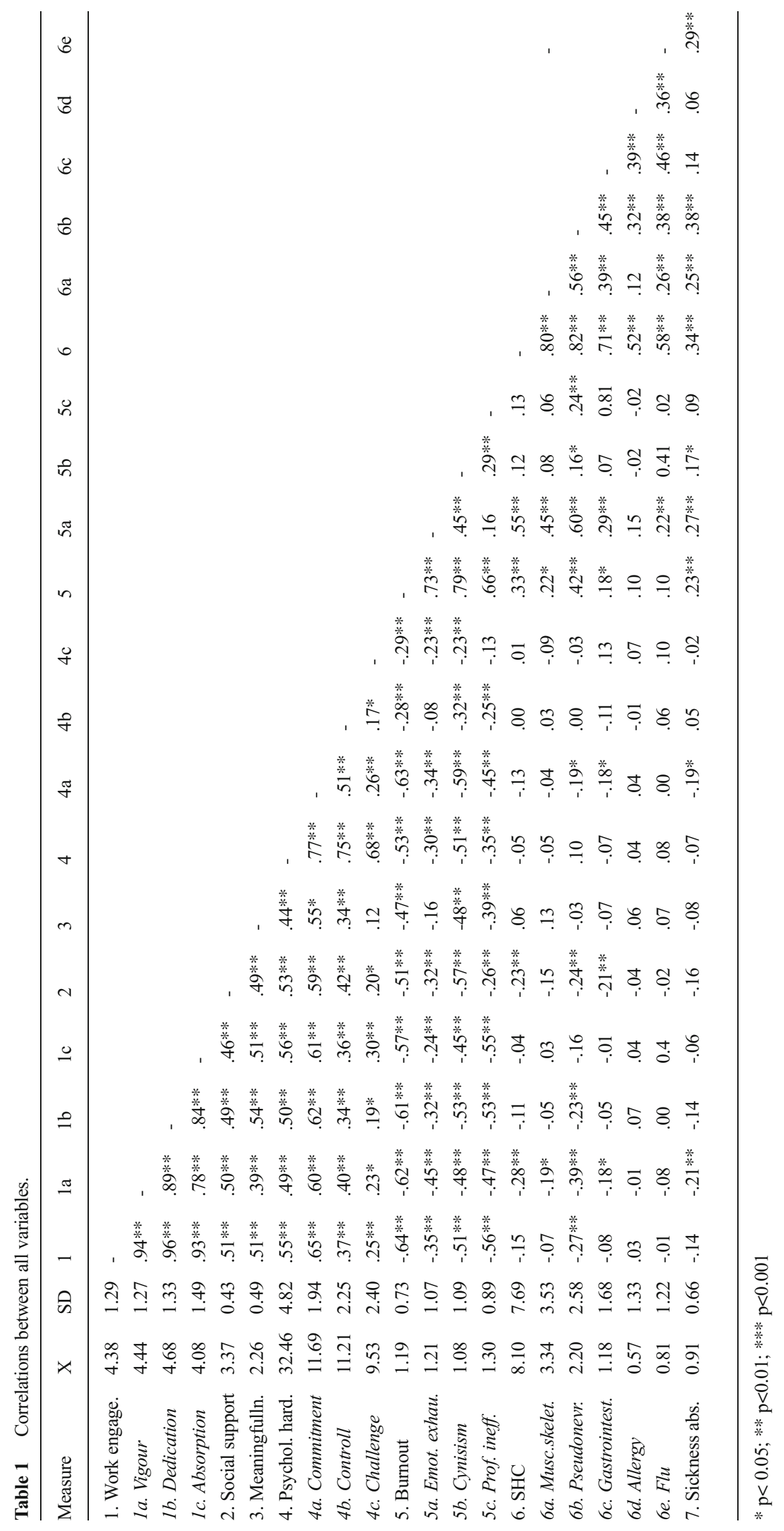


Table 2 Mean (X) and standard deviations (SD) of each subscale of Subjective Health Complaints.

\begin{tabular}{lll}
\hline & \multicolumn{2}{l}{ Subjective health complaints } \\
\hline Total & $\mathrm{X}$ & 8.1 \\
& $\mathrm{SD}$ & 7.70 \\
Musculoskeletal & $\mathrm{X}$ & 3.34 \\
& $\mathrm{SD}$ & 3.53 \\
Pseudoneurology & $\mathrm{X}$ & 2.20 \\
& $\mathrm{SD}$ & 2.58 \\
Gastrointestinal & $\mathrm{X}$ & 1.18 \\
& $\mathrm{SD}$ & 1.68 \\
Allergy & $\mathrm{X}$ & 0.57 \\
& $\mathrm{SD}$ & 1.33 \\
Flu & $\mathrm{X}$ & 0.81 \\
& $\mathrm{SD}$ & 1.22 \\
\hline
\end{tabular}

social support, and subjective health complaints (Table 4). For hardiness, commitment was the only dimension being significantly higher in the assault crime investigator group (Table 5).

\section{DISCUSSION}

The results provided support for hypothesis 1 , concerning the sample as a whole: That hardiness would predict the variance in burnout beyond that of the other buffers. The results also provided support for hypothesis 2 , examining group differences: That investigators of assault crime would report higher levels of hardiness than investigators of less offensive crimes. They also reported higher levels of social support, meaningfulness, and subjective health complaints.

As for hypothesis 1, psychological hardiness correlated strongly with the other predictors, but still contributed uniquely to explain the variance in burnout. This is, to our knowledge, a unique finding in both hardiness and police research. Previous research has not focused on investigators as a group, and thus little is known about what resilience factors are at play to cope with stress among this group. The commitment dimension is seemingly a particularly important resilience factor, and calls for further discussion.

While hardiness as a whole describes a growth-oriented response style to challenges, the commitment dimension is specifically characterized by a sense of meaningfulness, commitment to personal goals, and involvement in other people (Kobasa 1979). The latter is concurrent with another finding in the study, that social support also plays an important role in predicting the variance in burnout.

The ability of commitment to predict certain outcomes has been evident in several studies. In the final test of a tough military selection program, commitment predicted success, positive daily coping, as well as positive self-evaluations among the participants (Johnsen et al. 2013). It has also proved important in academic performance (Hystad et al. 2009; Sheard 2009).

As for hypothesis 2 , hardiness-commitment was again the only dimension in hardiness standing out as significant in the results: Of the three hardiness components, this was the only one where the two groups differed. Considering the existential foundation of hardiness, the findings in the current study support the notion that hardiness is the "operationalization of existential courage." Hardy individuals, and specifically those high in commitment, have an awareness of their own priorities and goals, as well as their social context, and have a tendency to assign meaningfulness to stressful events (Johnsen et al. 2013; Britt et al. 2001; Halama and Bakosova 2009). Assuming that the strain caused by working with assault investigation is heavier than for other types of investigation, the commitment trait would be a key resource for investigators in this field.

A study among returned soldiers on a peacekeeping mission to Bosnia showed similar findings to this. Soldiers high in hardiness assigned more meaning to the mission both during and after the experience (Britt et al. 2001). Moreover, soldiers

Table 3 Unstandardized coefficients (B), standard errors (SE B), beta values $(\beta)$, explained variance $\left(R^{2}\right)$, changed explained variance $\left(\Delta R^{2}\right)$, and $p$-values $(p)$ of the hierarchical regression analysis.

\begin{tabular}{|c|c|c|c|c|}
\hline & \multicolumn{4}{|c|}{ Burnout } \\
\hline & $\mathrm{B}$ & SE B & $\beta$ & $p$ \\
\hline \multicolumn{5}{|l|}{ Model 1} \\
\hline Age & .001 & .008 & .016 & .857 \\
\hline Police experience & -.050 & .042 & -.123 & .239 \\
\hline \multirow[t]{2}{*}{ Position experience } & .058 & .039 & .155 & .139 \\
\hline & & $\mathrm{R}^{2}=.019$ & & .485 \\
\hline \multicolumn{5}{|l|}{ Model 2} \\
\hline \multirow[t]{2}{*}{ Gender } & -.105 & .132 & -.070 & .428 \\
\hline & & $\mathrm{R}^{2}=.024$ & $\Delta \mathrm{R}^{2}=.005$ & .546 \\
\hline \multicolumn{5}{|l|}{ Model 3} \\
\hline Marital status & .302 & .139 & .168 & .032 \\
\hline \multirow[t]{2}{*}{ Social support } & -.952 & .136 & -.561 & .000 \\
\hline & & $\mathrm{R}^{2}=.30$ & $\Delta \mathrm{R}^{2}=.28$ & .000 \\
\hline \multicolumn{5}{|l|}{ Model 4} \\
\hline Meaningfulness & -.124 & .120 & -.083 & .303 \\
\hline \multirow[t]{2}{*}{ Work engagement } & -.282 & .045 & -.497 & .000 \\
\hline & & $\mathrm{R}^{2}=.51$ & $\Delta \mathrm{R}^{2}=.21$ & .000 \\
\hline \multicolumn{5}{|l|}{ Model 5} \\
\hline \multirow[t]{2}{*}{ Hardiness-commitment } & -.107 & .034 & -.282 & .002 \\
\hline & & $\mathrm{R}^{2}=.54$ & $\Delta \mathrm{R}^{2}=.036$ & .000 \\
\hline
\end{tabular}


Table 4 Mean values (X), standard deviations (SD), $t$-values $(t)$, degrees of freedom $(\mathrm{d} f)$, and $p$-values $(p)$ on the $t$-test between the two groups "Assault crime" $(\mathrm{AC})$ and "Others" $(\mathrm{O})$ on all variables.

\begin{tabular}{|c|c|c|c|c|c|c|}
\hline & & \multicolumn{2}{|l|}{ Group } & \multirow[t]{2}{*}{$t$} & \multirow[t]{2}{*}{$d f$} & \multirow[t]{2}{*}{$p$} \\
\hline & & $\mathrm{AC}(\mathrm{n}=71-78)$ & Others $(n=70-78)$ & & & \\
\hline \multirow[t]{2}{*}{ Burnout } & $\mathrm{X}$ & 1.13 & 1.27 & \multirow[t]{2}{*}{-1.13} & \multirow[t]{2}{*}{129} & \multirow[t]{2}{*}{.259} \\
\hline & SD & $(0.63)$ & $(0.82)$ & & & \\
\hline \multirow[t]{2}{*}{ Subj. health complaints } & $\mathrm{X}$ & 9.92 & 6.32 & \multirow[t]{2}{*}{2.97} & \multirow[t]{2}{*}{130} & \multirow[t]{2}{*}{.004} \\
\hline & SD & $(8.87)$ & $(5.86)$ & & & \\
\hline \multirow[t]{2}{*}{ Psychological hardiness } & $\mathrm{X}$ & 33.22 & 31.7 & \multirow[t]{2}{*}{1.97} & \multirow[t]{2}{*}{152} & \multirow[t]{2}{*}{.050} \\
\hline & SD & $(4.55)$ & $(4.99)$ & & & \\
\hline \multirow[t]{2}{*}{ Meaningfulness } & $\mathrm{X}$ & 2.37 & 2.15 & \multirow[t]{2}{*}{2.89} & \multirow[t]{2}{*}{152} & \multirow[t]{2}{*}{.004} \\
\hline & SD & $(0.43)$ & $(0.53)$ & & & \\
\hline \multirow[t]{2}{*}{ Social support } & $\mathrm{X}$ & 3.45 & 3.30 & \multirow[t]{2}{*}{2.22} & \multirow[t]{2}{*}{148} & \multirow[t]{2}{*}{.028} \\
\hline & SD & $(0.44)$ & $(0.41)$ & & & \\
\hline \multirow[t]{2}{*}{ Work engagement } & $\mathrm{X}$ & 4.56 & 4.21 & \multirow[t]{2}{*}{1.69} & \multirow[t]{2}{*}{142} & \multirow[t]{2}{*}{.092} \\
\hline & SD & $(1.10)$ & $(1.43)$ & & & \\
\hline
\end{tabular}

who were exposed to the destructions of the war reported benefiting more from partaking in the mission than soldiers located in remote areas. In concurrence with the findings in the current study, it seems that hardy individuals assign meaning to circumstances that for others may be perceived as stressful. This may explain why the results showed no differences between the two groups on levels of burnout, questioning the assumption that investigators of assault crime would experience more stress-reactions due to their work tasks. It is fair to assume that the high level of hardinesscommitment among investigators of assault crime enables them to reframe challenging situations as growth opportunities, enhance commitment to solve cases and restore justice to victims, as well as ascribing meaning to seemingly meaningless cases. This finding adds to the growing body of research on the potential benefits that can be derived from stressful events (Britt et al. 2001).

However, the comparison between the two groups on all the variables provided another interesting finding that brings to attention an aspect of hardiness that has not received attention in hardiness research. There were no significant differences on burnout and sickness absence scores between the investigator groups. The assault crime investigators did, however, report significantly higher scores on subjective health complaints, with musculoskeletal pain receiving highest scores. The high scores on this sub-category are consistent with the majority of prevalence studies for subjective health complaints (Ihlebæk et al. 2002; Wilhelmsen et al. 2007). However, the respondents in the current study reported levels of sickness absence well below average for the general population (NAV.no), which is a bit puzzling, considering the fact that musculoskeletal complaints is by far the most common cause for sick leave (Eriksen et al. 1998). It begs the question of whether all aspects of hardiness are unequivocally positive.
A previous police study conducted by Berg and colleagues (2006) similarly found police workers to report higher scores on subjective health complaints than physicians, but lower scores on burnout. This may indicate that for this particular group, work stressors are not translated into self-reports of emotional exhaustion, but are rather deflected in physical complaints. The self-perception held by hardy individuals that they are capable of coping with challenges, may lead to neglecting signals of work strain, which in turn results in subjective health complaints. If a high level of commitment hinders one from recognizing when the work strain surpasses one's capacity, this trait may in fact result in more complaints. The high level of commitment may lead the employee to ignore symptoms of unhealthy strain, and come to work when others would have stayed at home to recover. This last consequence is not a problem as such, as low levels of sickness absence usually are favorable to the organization. However, if this results in long-term sick leave further down the road, or

Table 5 Mean values (X), standard deviations (SD), $t$-values $(t)$, degrees of freedom $(\mathrm{d} f)$, and $p$-values $(p)$ on the $t$-test between the two groups "Assault crime" (AC) and "Others" $(\mathrm{O})$ on the dimensions of hardiness.

\begin{tabular}{lllllll}
\hline & & \multicolumn{2}{l}{ Group $(\mathrm{n}=77-78)$} & $t$ & $d f$ & $p$ \\
\cline { 3 - 5 } & & AC & Others & & & \\
\hline Commitment & $\mathrm{X}$ & 12.08 & 11.29 & 2.57 & 154 & .011 \\
& $\mathrm{SD}$ & $(1.74)$ & $(2.05)$ & & & \\
Control & $\mathrm{X}$ & 11.42 & 11.00 & 1.18 & 154 & .242 \\
& $\mathrm{SD}$ & $(2.23)$ & $(2.27)$ & & & \\
Challenge & & 9.7 & 9.35 & 0.91 & 152 & .366 \\
& $\mathrm{SD}$ & $(2.29)$ & $(2.50)$ & & & \\
\hline
\end{tabular}


even employees leaving the work force due to ignoring the initial symptoms, it becomes an organizational problem. There are not enough data in the current study to explore these assumptions properly, but further research on hardiness should expand the traditional scope to include potentially negative consequences of being high in hardiness.

\section{CONCLUSION}

\section{Study limitations}

As the data were gathered at only one time-point, concurrent measurement may have influenced the statistical relationship between some of the variables. Additionally, the study does not include direct measures of stressors, which makes us unable to examine the relationship between workload or frequency of critical incidents, and stress outcomes. Also, the study population was from a city, where police work is organized differently than in the rural areas. Generalizing the findings in the study to smaller police districts should be done with care.

Lastly, the career path of a police officer can go through different parts of the police organization, which makes it difficult to isolate the effect of working in one particular field at a given time. Type of previous experience may be a confounding variable for how to handle work strain, but this has not been explored in the current study. Lack of detailed background information makes it difficult to take this factor into account.

\section{Recommendations}

The findings in this study give practical implications for recruitment and selection of police investigators of assault crime, as well as for cultivating buffers in the psychosocial work environment. The study supports that hardiness, and in particular commitment, is a unique factor explaining the variance in burnout in a demanding work setting. This suggests that screening applicants for hardiness in a recruitment process may predict their ability to cope with the stressors of investigating assault crime. The findings also highlight the importance of social support in the work environment. Colleague and leader support is a psychosocial aspect that should be well facilitated in the workplace by the employer and department leaders, particularly in departments where investigators are assumed to experience high work strain.

However, the study alternatively points to a little researched aspect of hardiness-commitment, if it is the case that employees ignore illness signs in order to see through his or her professional commitments. The potential mechanisms involved in this should be further examined in order to discover whether there are certain circumstances under which hardiness leads to negative health outcomes, such as prolonged sickness symptoms.
Compliance with ethical standards The study was submitted to the Norwegian Regional Ethics Committee. However, because the study was anonymous and did not collect sensitive data, the committee deemed the study not to require ethical approval.

Open Access This article is distributed under the terms of the Creative Commons Attribution 4.0 International License (http:// creativecommons.org/licenses/by/4.0/), which permits unrestricted use, distribution, and reproduction in any medium, provided you give appropriate credit to the original author(s) and the source, provide a link to the Creative Commons license, and indicate if changes were made.

\section{REFERENCES}

Andrew ME, McCanlies EC, Burchfiel CM, Charles LE, Hartley TA, Fekedulegn D, Violanti JM (2008) Hardiness and psychological distress in a cohort of police officers. Int J Emerg Ment Health 10(2):137-147

Bartone PT (2006) Resilience under military operational stress: can leaders influence hardiness? Mil Psychol 18(S):S131

Berg AM, Hem E, Lau B, Ekeberg O (2006) An exploration of job stress and health in the Norwegian police service: a cross sectional study. $\mathrm{J}$ Occup Med Toxicol 1(1):26

Biggs A, Brough P, Barbour JP (2014) Exposure to extraorganizational stressors: impact on mental health and organizational perceptions for police officers. Int J Stress Manag 21(3):255-282. doi:10.1037/ a0037297

Britt TW, Adler AB, Bartone PT (2001) Deriving benefits from stressful events: the role of engagement in meaningful work and hardiness. J Occup Health Psychol 6(1):53-63

Brown J, Fielding J, Grover J (1999) Distinguishing traumatic, vicarious and routine operational stressor exposure and attendant adverse consequences in a sample of police officers. Work Stress 13(4):312-325

DeLongis A, Folkman S, Lazarus RS (1988) The impact of daily stress on health and mood: psychological and social resources as mediators. J Pers Soc Psychol 54(3):486

Eriksen HR, Ursin H (1999) Subjective health complaints: Is coping more important than control? Work Stress 13(3):238-252

Eriksen HR, Svendsrod R, Ursin G, Ursin H (1998) Prevalence of subjective health complaints in the Nordic European countries in 1993. Eur J Public Health 8(4):294-298

Eriksen HR, Ihlebæk C, Ursin H (1999) A scoring system for subjective health complaints (SHC). Scand J Public Health 27(1):63-72

Eschleman KJ, Bowling NA, Alarcon GM (2010) A meta-analytic examination of hardiness. Int J Stress Manag 17(4):277-307

Gillet N, Huart I, Colombat P, Fouquereau E (2013) Perceived organizational support, motivation, and engagement among police officers. Prof Psychol Res Pract 44(1):46-55. doi:10.1037/a0030066

Halama P, Bakosova K (2009) Meaning in life as a moderator of the relationship between perceived stress and coping. Stud Psychol 51(2-3):143-148

Hystad SW, Eid J, Laberg JC, Johnsen BH, Bartone PT (2009) Academic stress and health: exploring the moderating role of personality hardiness. Scand J Educ Res 53(5):421-429

Hystad SW, Eid J, Johnsen BH, Laberg JC, Bartone PT (2010) Psychometric properties of the revised Norwegian dispositional resilience (hardiness) scale. Scand J Psychol 51(3):237-245

Ihlebæk C, Eriksen HR, Ursin H (2002) Prevalence of subjective health complaints (SHC) in Norway. Scand J Public Health 30(1):20-29

Ihlebæk C, Eriksen HR, Ursin H (2004) SHC - et måleinstrument for subjektive helseplager. Tidsskrift for Norsk Psykologforening (41): 385-387 
Johnsen BH, Bartone P, Sandvik AM, Gjeldnes R, Morken AM, Hystad SW, Stornæs AV (2013) Psychological hardiness predicts success in a Norwegian armed forces border patrol selection course. Int J Sel Assess 21(4):368-375

Johnson JV, Hall EM (1988) Job strain, work place social support, and cardiovascular disease: a cross-sectional study of a random sample of the Swedish working population. Am J Public Health 78(10): 1336-1342

Jourdain G, Chênevert D (2010) Job demands-resources, burnout and intention to leave the nursing profession: a questionnaire survey. Int J Nurs Stud 47(6):709-722

Karasek R, Brisson C, Kawakami N, Houtman I, Bongers P, Amick B (1998) The Job Content Questionnaire (JCQ): an instrument for internationally comparative assessments of psychosocial job characteristics. J Occup Health Psychol 3(4):322-355

Kobasa SC (1979) Stressful life events, personality, and health: an inquiry into hardiness. J Pers Soc Psychol 37(1):1-11

Kobasa SC, Maddi SR, Kahn S (1982) Hardiness and health: a prospective study. J Pers Soc Psychol 42(1):168-177

Maddi SR (2002) The story of hardiness: twenty years of theorizing, research, and practice. Consult Psychol J Pract Res 54(3):173

Martinussen M, Richardsen AM, Burke RJ (2007) Job demands, job resources, and burnout among police officers. J Crim Just 35(3): 239-249

Maslach C, Jackson SE (1981) The measurement of experienced burnout. J Organ Behav 2(2):99-113

Maslach C, Jackson SE, Leiter MP, Schaufeli W, Schwab RL (1986) Maslach Burnout Inventory. Instrument and scoring guides

Maslach C, Schaufeli WB, Leiter MP (2001) Job burnout. Annu Rev Psychol 52(1):397-422. doi:10.1146/annurev.psych.52.1.397

NAV.no https://www.nav.no/no/NAV+og+samfunn/Statistikk/ Sykefravar+-+statistikk/Tabeller/Legemeldt+sykefrav\%C3\%A6r+ i+prosent+2+kvartal+2005-2014.+Totalt $\% 2 \mathrm{C}+$ alder+og+kj\%C3\% B8nn..391461.cms. Last visited: October 31th, 2014
Piko BF (2006) Burnout, role conflict, job satisfaction and psychosocial health among Hungarian health care staff: a questionnaire survey. Int J Nurs Stud 43(3):311-318

Richardsen AM, Martinussen M (2005) Factorial validity and consistency of the MBI-GS across occupational groups in Norway. Int J Stress Manag 12(3):289-297

Sandal GM, Larsen S, Matthiesen, Pallesen S, Remme T (2006) Arbeidsplassen under lupen: HMS-kartlegging i Hordaland politidistrikt 2006. Universitetet i Bergen, Bergen

Schaufeli WB, Bakker AB (2003) Utrecht work engagement scale (UWES) preliminary manual [Version 1, November 2003]. Utrecht University: Occupational Health Psychology Unit

Schaufeli W, Enzmann D (1998) The burnout companion to study and practice: a critical analysis. CRC press

Schaufeli WB, Bakker AB, Salanova M (2006) The measurement of work engagement with a short questionnaire. Educ Psychol Meas 66(4):701-716

Schaufeli WB, Leiter MP, Maslach C (2008) Burnout: 35 years of research and practice. Career Dev Int 14(3):204-220

Sheard M (2009) Hardiness commitment, gender, and age differentiate university academic performance. Br J Educ Psychol 79(1):189-204

Southwick SM, Vythilingam M, Charney DS (2005) The psychobiology of depression and resilience to stress: implications for prevention and treatment. Annu Rev Clin Psychol 1:255-291

Wilhelmsen I, Mulindi S, Sankok D, Wilhelmsen AB, Eriksen HR, Ursin $H$ (2007) Subjective health complaints are more prevalent in Maasais than in Norwegians. Nord J Psychiatry 61(4):304-309

Zach S, Raviv S, Inbar R (2007) The benefits of a graduated training program for security officers on physical performance in stressful situations. Int J Stress Manag 14(4):350-369

Zapf D, Seifert C, Schmutte B, Mertini H, Holz M (2001) Emotion work and job stressors and their effects on burnout. Psychol Health 16(5): $527-545$ 